\title{
TEMPO E CONSTRUÇÃO DO SOCIAL
}

\author{
Julieta Beatriz Ramos Desaulniers*
}

SÍNTESE - Esse texto comenta alguns dos pressupostos do pensamento científico e expõe como alguns cientistas têm procedido em seus estudos e pesquisas, para capturar as principais dimensões do tempo que configuram à construção do social, ainda, tece algumas considerações sobre as possibilidades de convergência, entre as diversas áreas das Ciências Humanas e Sociais, quando pesquisas privilegiam o tempo - uma categoria de análise de caráter universal e, por isso, capaz de articular as várias áreas da ciência.
ABSTRACT - This text comments on some of the assumptions of scientific thought and shows how some scientists have conducted themselves in their studies and research, in order to capture the main dimensions of time that configure the construction about the social context. Further, it makes some considerations about the possibilities of convergencies between the several areas of the Human and Social Sciences, when research focusses on time, which is a category of analysis with universal features and therefore capable of articulating the several areas of science.

\section{1 - Introdução}

Na ciência moderna, o pensamento científico funda-se sobre o projeto através da "mediação do objeto pelo sujeito", ${ }^{1}$ baseando-se no vetor epistemológico que vai do racional ao real. Assim, nesse novo espírito, a experiência científica é uma razão confirmada, que é "apreendida pela teoria antes de ser descoberta pela observação". ${ }^{2}$

Nessa perspectiva, mesmo se é o "objeto quem fornece os elementos à prova", o qual se apresenta "como um complexo de relações", a proposição de "juízos sintéticos a priori" é indispensável para se restituir ao fenômeno todas as suas solidariedades e, ao mesmo tempo, "romper com o nosso conceito de repouso". ${ }^{3}$

Esse pressuposto da ciência contemporânea vale-se da idéia que não é o ser que ilustra a relação, mas ao contrário, é "a relação que ilustra o ser". ${ }^{4}$ Sendo o fe-

* Pontifícia Universidade Católica do Rio Grande do Sul, PUCRS.

1 BACHELARD, Gaston. O novo espirito científico. Porto: Edições Saber, 1986. p. 18. Algumas das considerações expostas a seguir foram apresentadas e debatidas na XVII Reunião Anual da Associação Nacional de Pós-Graduação em Educaçāo (ANPEd), em Caxambú/MG, out./94.

2 Idem, p. 14.

3 BACHELARD, op. cit., p.18 e 101.

4 Idem, p. 102.

\begin{tabular}{|l|l|l|l|l|l|}
\hline VERITAS & Por to Alegre & v. 41 & $\mathrm{n}^{0} 162$ & Junho 1996 & p. $355-360$ \\
\hline
\end{tabular}


coisas. Ele não existe em estado puro, mas "é constituído do cenário que encerra". ${ }^{10}$ Sendo assim, é necessário distinguir os vários niveis de tempo, em que os fenômenos se constroem. Nesse sentido, conforme Braudel, é possível distinguir três níveis: a curtạ duração (o fato ocorrencial, cronológico); a duração intermediária (os ciclos, por exemplo) e a longa duração (mentalidades, tecnologia...).

Mais recentemente, um outro elemento que está sendo considerado nas pesquisas refere-se à preocupação em detectar os momentos de ruptura dos fenômenos. De fato para Foucault - que segue as referencias de ilustres estudiosos como Bachelard, Canguilhem e Koyré - "foi a descontinuidade que mudou de status". Antes, "era o estigma da dispersão temporal que o historiador tinha a seu cargo suprimir da História" e, na atualidade, tal dimensão tornou-se "um dos elementos fundamentais ${ }^{111}$ de toda análise que pretende abordar o fenômeno, em suas dimensões históricas.

A noção de descontinuidade, em alguma medida, é paradoxal "pois é ao mesmo tempo instrumento e objeto de pesquisa", além de exercer um tríplice papel: 1) "constitui uma ação deliberada do historiador", visto que ele tem de fixar por meio de algum critério as periodizações que lhe convém; 2) "é também o resultado da descrição", pois o que se pretende descobrir são os limites de um processo e demais aspectos que configurem rupturas; 3) é um conceito em constante construção, pois "toma uma forma e uma função diferentes, conforme o domínio e o nível aos quais é atribuída". ${ }^{12}$

As considerações expostas até aqui destacaram as novas tendências ao se analisar o tempo, as quais procuram salientar os vários niveis em que os fenômenos se constituem, além de inserir a ruptura e a descontinuidade como elemento que pertencem à configuração de suas trajetórias.

As contribuições de Bachelard referentes ao tempo são também muito valiosas, o qual enfoca tal categoria de análise a partir da dialética da duração. Do seu ponto de vista, parece-lhe "impossivel não reconhecer a necessidade de basear a vida complexa numa pluralidade de durações que não têm nem o mesmo ritmo, nem a mesma solidez de encadeamento, nem o mesmo poder de continuidade". ${ }^{13}$

Observa o autor que "apenas aquilo que tem razões para recomeçar" permanece no tempo, sendo que a sua construção basea-se em esforços rítmicos. Os ritmos, segundo ele, caracterizam-se como um "sistema de instantes", ${ }^{14}$ sendo então necessário admitir-se a "alternância temporal". ${ }^{15}$

Quanto ao tempo vivido, pensado ou ensinado, é necessário considerá-lo como obstáculo e como auxílio, além de se ganhar e se perder no tempo alternadamente. Tais elementos indicam que o tempo se constitui de uma série de rupturas.

10 FOUROUET, François. "Um novo espaço-tempo". In: LACOSTE, Yves (coord.). Ler Braudel. Campinas: Papirus, 1989. p. 86.

11 FOUCAULT, Michel. "História e descontinuidade". In: SLVA, op. cit., p. 57.

12 FOUCAULT, Michel. op. cit., p. 57 e 58.

13 BACHELARD, Gaston. A dialética da duração. São Paulo: Ática, 1988. p. 7.

14 BACHELARD, op. cit., p. 8 e 9.

15 É a noção de descontinuidade que, mais tarde, foi aplicada por Foucault em suas investigações, conforme algumas referências feitas anteriormente. 
Outra abordagem a ser considerada é a de Maurice Halbawachs, que "abre um novo caminho para o estudo sociológico da vida quotidiana", ${ }^{16}$ ao refletir sobre a memória e a duração. É, na verdade, uma análise das memórias que esconde "uma definição do tempo", onde os fenômenos não se desenrolam mais em um meio homogêneo e uniforme. ${ }^{17}$

$O$ depoimento não tem sentido senão em relação a um grupo e depende do quadro de referência no qual evoluem o grupo e o indivíduo que os atestam. Já a lembrança é concebida "como a fronteira e o limite" [...] "de todas as interferências coletivas", que correspondem à vida dos grupos. ${ }^{18}$

A distinção que o autor faz entre "memória histórica" e "memória coletiva" é igualmente esclarecedora, mesmo se ficou incompleta em seus estudos. A primeira "supõe a reconstrução dos dados fornecidos pelo presente da vida social e é projetada no passado reinventado", enquanto a memória coletiva "recompõe magicamente o passado" ${ }^{19}$

A história de vida enquanto um método biográfico, "cujo objetivo é - a partir da totalidade sintética que é o discurso específico de um indivíduo - reconstruir uma experiência humana vivida em grupo e de tendência universal", constitui-se numa forma de resgatar o conteúdo da memória coletiva. ${ }^{20}$

Assim, a história de vida permite a objetivação de fenômenos que, até bem pouco tempo, eram considerados como subjetivos, desde que se utilize "técnicas operacionais que possibilitem alcançar esses níveis de análise". ${ }^{21}$

Também, quanto à reconstrução dos valores, conflitos e arquétipos, em função da sua complexidade, sugere-se a "reconstrução dos testemunhos qualitativos" que se referem ao tempo pensado e ao tempo vivido. Assim, com histórias de vida que expressem a subjetividade do indivíduo - repleta de uma multiplicidade de instantes e por isso não retém a totalidade - é possivel reconstruir a dinâmica de algumas das múltiplas idéias referentes a um grupo social determinado. ${ }^{22}$

\section{3 - Tempo e construção do social}

Os estudos e investigações que desenvolvo junto à sub-linha de pesquisa "Formação, trabalho e instituição", com base no projeto "A formação em escolas de ofício católicas do RS, 1890/1990", supõem uma estreita articulação entre as perspectivas sociológica e histórica.

Sem dúvida, para se apreender o movimento desse processo realizado em instituição escolar, assim como a sua inserção na sociedade enquanto uma das esferas que a produz, faz-se necessária a análise das inúmeras articulações estabeleci-

16 HALBWACHS, Maurice. A memória coletiva. São Paulo: Vértice, 1990. p. 9.

17 Idem, p. 13.

18 Idem, p. 14.

19. Idem, p. 15.

20 MARRE, Jacques Léon. "História de vida e método biográfico". In: Cademos de Sociologia. Porto Alegre: PPGS/UFRGS, 1989. p. 89 e 90.

21

Idem, p. 125.

22 Idem, p. 125 e 126. 
das no decorrer do tempo, as quais são sustentadas através de relações de disputa pelo poder, tanto no campo educacional como entre os outros campos do espaço social, em especial, com o próprio campo do poder. ${ }^{23}$

Ainda, esse é um dos problemas que só no tempo longo pode ser resolvido, significando dizer que essa pesquisa é frutífera, desde que se privilegie a longa duração - uma das dimensões do tempo, enquanto uma das categorias de análise.

A temática dessa pesquisa - central no campo educativo - revela-se, igualmente, muito frutífera, ao ser investigada numa perspectiva interdisciplinar. Por isso, elaborou-se e está em andamento um projeto integrado, ${ }^{24}$ que envolve algumas instituições universitárias (UFRGS, PUCRS e UNISINOS/RS/BRASIL), com a participação de pesquisadores de distintas áreas das Ciências Humanas e Sociais como Sociologia, Histónia e Educação.

Com o título "Urbanidade e Cidadania: processos de formação e de instauração de saberes", tal projeto articula várias sub-linhas de pesquisa, que privilegiam o tempo como uma das categorias centrais ao investigar, a partir de cada uma das problemáticas selecionadas, como tem se instaurado a formação que vem construindo o cidadão no decorrer do séc. XX, no Estado do Rio Grande do Sul. Os sub-projetos que materializam as várias problemáticas de estudo são os seguintes:

* Formar o cidadão: uma proposta da escola de ofício católica

* As iniciativas assistenciais e a formação do cidadão

* As ações e práticas formativas da medicina social no Rio Grande do Sul

* A constituição dos agentes do Estado: contribuições para a formação do cidadão

* Sindicalismo, estratégias pedagógicas e a formação operária

\section{4 - Considerações finais}

A necessidade de articulação entre as disciplinas é evidente, já existindo vários pontos de consenso junto aos estudiosos sobre essa questão. O que importa no momento, mais do que o debate em torno das recíprocas fronteiras, são as alternativas que possibilitem a convergência entre as diversas áreas das Ciências Humanas e Sociais.

Assim, há mais possibilidades de se romper com a postura que essa área do conhecimento tem assumido ultimamente, distanciando-se dos debates étnicos e políticos vividos pela sociedade, constituindo-se em auto-referência feita por especialistas para especialistas. Isso representa um outro problema igualmente grave, que é o da qualidade discutivel de suas produções. ${ }^{25}$

Após a década de sessenta o lugar de maior interação entre a Sociologia e a História, e um dos mais promissores, é o da Educação. Sendo assim, o desenvolvimento de linhas de pesquisa com projetos referentes ao campo educativo, que pri-

23 Essa abordagem utiliza-se do referencial de análise proposto por Pierre Bourdieu.

24 O referido projeto integrado conta com financiamento do CNPq e FAPERGS.

25 CAПLÉ, Alain. "La démission des Sciences Sociales". In: Revue Sciences Sociales, Paris, n. 38, 1994. p. 37. 
vilegiem categorias de análise como a categoria tempo, por exemplo, têm condições de integrar as várias perspectivas dessa área do conhecimento.

Desse modo, espera-se que as Ciências Humanas e Sociais readquiram, em parte, a sua capacidade de anunciar as tendências referentes à construção do social, como já aconteceu com seus fundadores (É. Durkheim, Max Weber e Karl Marx), procurando basear-se numa perspectiva que, como forma de superação do formalismo e do utilitarismo, retome as suas origens no sentido de participar da criatividade política da atualidade. ${ }^{26}$

26 CALLÉ, op. cit., p. 36. 